\title{
Митракова А.B. \\ Особенности архитектурно-строительных решений терема в с. Асташово Костромской обл.
}

Санкт-Петербургский государственный архитектурно-строительный университет (Россия, Санкт-Петербург)

doi: 10.18411/lj-04-2021-31

\section{Аннотация}

В статье проанализированы конструктивные особенности кровли памятника деревянного зодчества: терема в с. Асташово. Приведено подробное описание элементов и узлов стропильной системы. Доказано, что конструкция предварительно собиралась при изготовлении элементов.

Ключевые слова: терем, стропильная система, памятник деревянного зодчества, реставрация, реконструкция.

\section{Abstract}

The article analyzes the structural features of the roof of the monument of wooden architecture: terem in the village of Astashovo. A detailed description of the elements and components of the truss system is given. It is proved that the design was previously assembled during the manufacture of the elements.

Keywords: terem, truss system, monument of wooden architecture, restoration, reconstruction.

Деревянная архитектура в течение многих столетий создавала облик городов и сёл. Постройки многообразны по своим функциям, назначению, особенностям использования древесины как строительного материала. На сегодняшний день объекты деревянного зодчества являются архитектурным наследием и самым главным проявлением национальной культуры [1, 2]. При этом ситуация, сложившаяся с обеспечением сохранности памятников деревянного зодчества, критическая. На протяжении последних десятилетий стремительно разрушаются памятники федерального, регионального и местного значения. Всего за 1960-2020 гг. утрачено 1276 памятников. Наибольшее количество утраченных объектов выявлено в Костромской, Архангельской областях и Забайкальском крае - 663 ед. Это составляет четверть (25\%) всех памятников деревянного зодчества, стоящих на учете в данных субъектах Федерации [3]. Памятники деревянного зодчества, находящиеся вне населенных пунктов, являются самой уязвимой группой. Их существование напрямую зависит от наличия поблизости дорог и жилья. Актуальным является включение памятника в туристические маршруты, отнесение территории к достопримечательным местам. В таком случае памятник попадает под пристальный контроль специалистов. Именно регулярный мониторинг за состоянием памятника даст возможность сохранить его от вредоносного воздействия насекомых и дереворазрушающих грибов $[4,5,6]$.

Примером такого положительного опыта является реставрация терема в с. Асташово Костромской области [7]. Благодаря труду энтузиастов удалось привлечь к реставрационным работам опытных архитекторов, реставраторов и здание было восстановлено в первоначальном виде. В советское время в тереме находилось много учреждений, но ремонтные работы и перепланировки в нем не проводились и благодаря этому сохранилась общая планировка, деревянные колонны, балки перекрытий. В процессе работ было заменено 60\% старых бревен. Для замены утрат была заготовлена ель с аналогичными возрастными характеристиками и параметрами. Используя приемы реставрации получилось избежать полной замены непригодных бревен, а вычинить их, выбрав гнилую древесину и присоединить свежую, пригодную для эксплуатации. (см. рис. 1). Места стыков законопачивались паклей, запечатывая 
щели, чтобы избежать появления конденсата и защитить сруб от гниения и преждевременного разрушения. Большая часть конструкции осталась прежней, но пришлось полностью заново отстроить 24-метровую башню в левой части здания. Удалось восстановить более тысячи различных резных элементов.

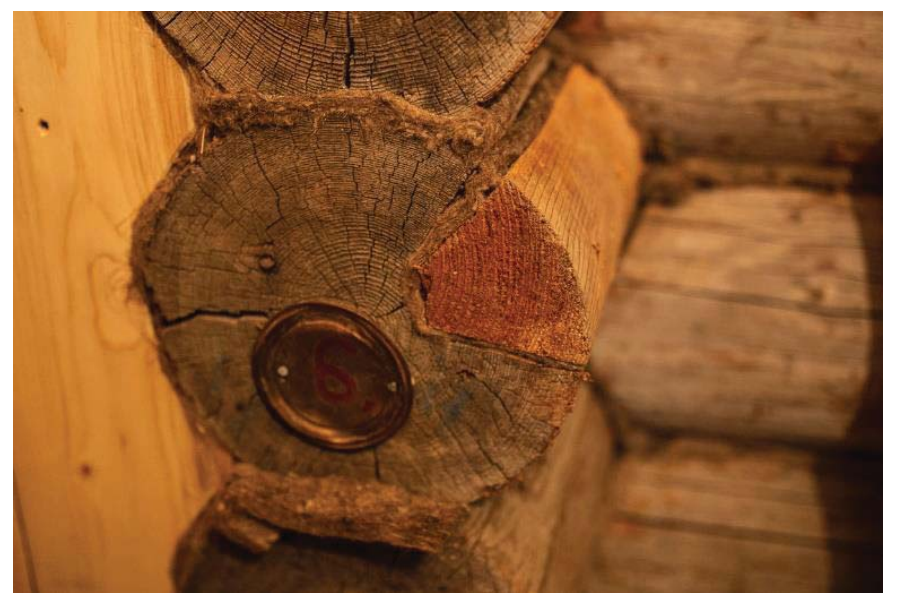

Рис. 1. Отреставрированное бревно

Здание было построено в 1897 году по проекту архитектора И.В. Ропета. Здание имеет размер в плане приблизительно $30 \times 25$ м. На рис.2 приведены планы первого и второго этажей, полученные из архитектурной энциклопедии «Русское деревянное зодчество XIV-XX веков», хранящаяся в музее-тереме.

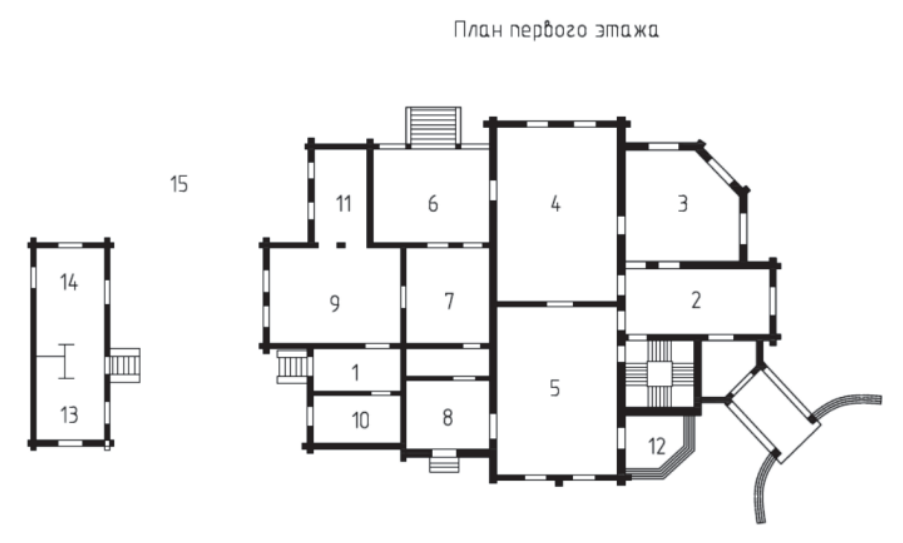

Ппан 8̊торого эпажа

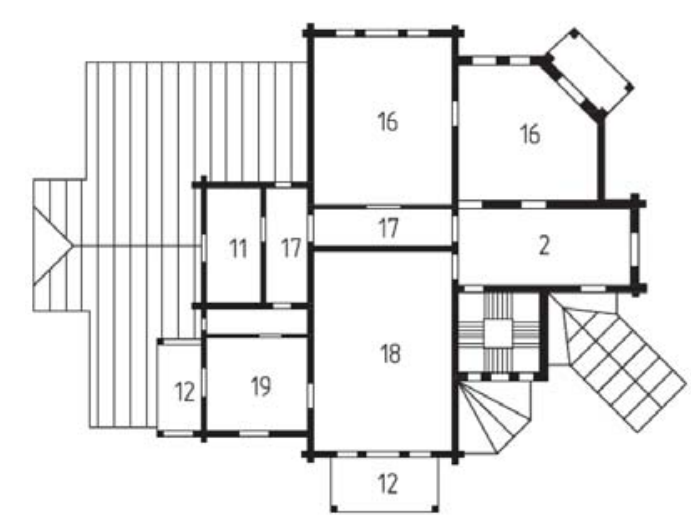

Рис.2 Планы этажей (1.Сени; 2.Передняя; 3.Гостиная; 4.Столовая; 5.Кабинет; б.Летняя столовая;

7.Буфет; 8.Библиотека; 9.Кухня; 10.Чулан; 11.Комната прислуги; 12.Балкон; 13.Людская; 14.Прачечная; 15.Хоз.службы; 16. Запасная; 17.Коридор; 18.Спальня; 19.Уборная) 
Крыша в Тереме в с. Асташово является прямоскатной. На рис. 3 представлен план кровли из архитектурной энциклопедии «Русское деревянное зодчество XIV-XX веков». Конек кровли терема расположен на отметке $+13,000$ от уровня земли.

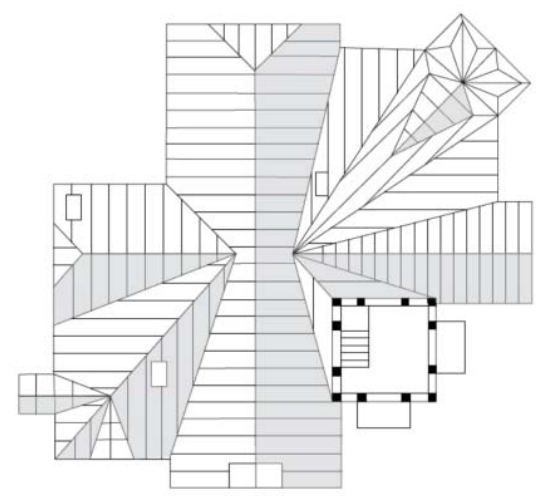

Рис.3 План кровельного покрытия

Кровля является наиболее ответственной конструктивной частью здания. Ее целостность обеспечивает защиту всей конструкции от неблагоприятного воздействия окружающей среды и гарантирует долговечность здания [8]. Скорость повреждения и состояние кровельных материалов зависит также от расположения здания относительно частей света. Так, поверхность кровли терема, обращенная на север, интенсивнее обросла лишайником, и более других частей крыши пришла в негодность. Южные скаты древесины кровли подвергались деструкции от интенсивной солнечной радиации. Древесина кровли сохранилась лучше, чем материал самого сруба: объем нового материала не превысил 30\%. Подлинные балки, послужили образцами для изготовления недостающих.

Результаты изучения конструктивных особенностей кровли терема показали, что строительным материалом кровельного покрытия, как и всех конструкций терема в целом, является ель. Содержащиеся смолы в хвойных породах древесины обладают неярко выраженными антисептическими свойствам, наличие которых способствует долговечности конструкций из дерева. Верхние концы стропил сходятся в коньке, взаимно поддерживаясь на весу, опираясь друг на друга, а нижние опираются на деревянные стены терема. Конструкция состоит из двух стропильных ног с затяжкой (рис.4), она фиксирует их положение, не давая стропилам расходиться в сторону и увеличивать угол. В коньковом соединении крепятся стропильные ноги вполдерева: достаточно простым и надежным способом. На стропилах кровли обнаружены следы, которые говорят о том, что первоначально планировалась другая конструкция кровли, по видимому более простая, а потом она была изменена чтобы вместить башенку и новое завершение балкона.

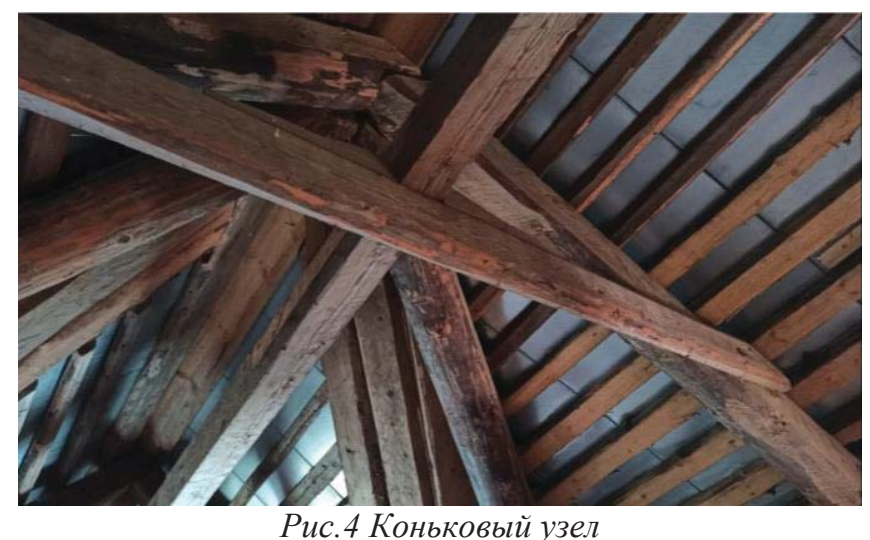

Рис.4 Коньковыци узел 
Накостные ноги лежат по крайней мере на двух неподвижных опорах, опираясь на них своими нижними концами (рис.5). Верхние концы же взаимно поддерживаются на весу, опираясь друг на друга.

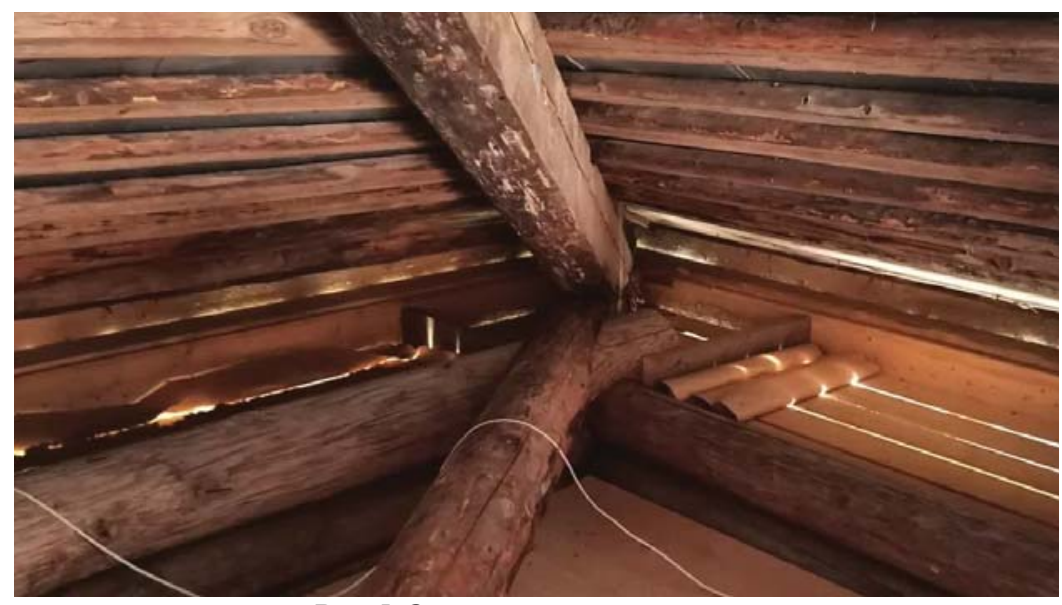

Рис.5 Опирание накосной ноги

Материал стропильных ног был обновлен на 30\%. Сохранились балки чердачного перекрытия, длиной 14 м. Поверх стропильных ног установлена разбежная однослойная обрешетка. Почти все элементы кровли были заменены частично на новые при реконструкции, кроме стропильных ног. Это хорошо видно невооруженным взглядом. На сохранившихся элементах кровли видна грубая теска топором, а также на них имеется маркировка (рис.6).

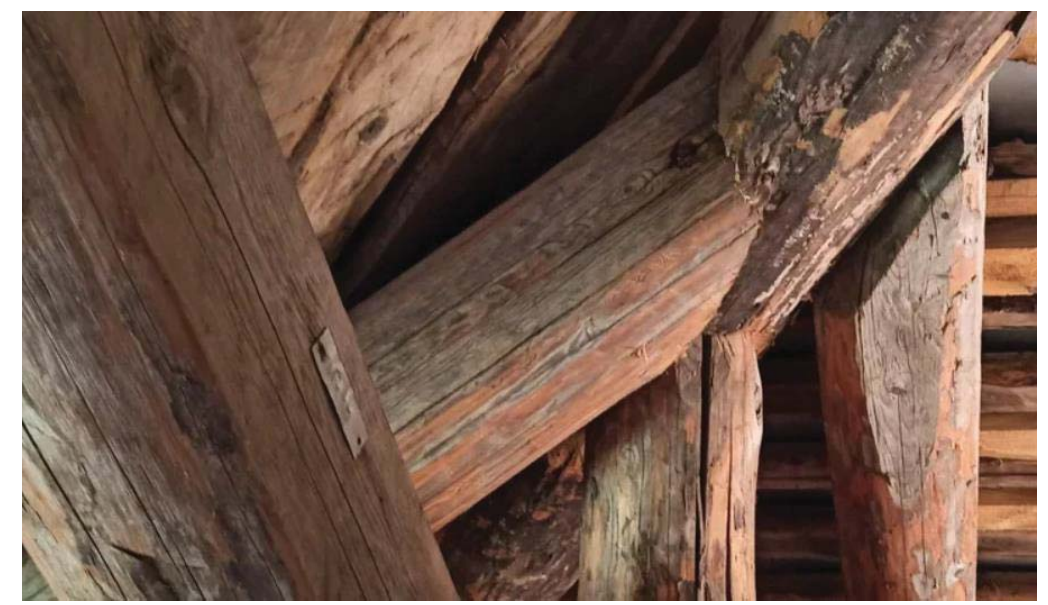

Рис.6 Маркировка элементов

Различные маркировки, метки на элементах сруба и кровли подтверждают версию о том, что конструкция предварительно собиралась, при выполнении деревянных элементов, а потом в разобранном виде была доставлена на место строительства и собрана вновь. Использование природных антисептиков - бересты в кровельном покрытии позволило сохранить деревянные элементы кровли. Отсутствие перепланировок в здании с внедрением в строительный материал позволило сохранить некоторые несущие элементы.

$$
* * *
$$

1. А.Ю. Косенков. Возведение сруба и традиционные приемы рубки. Традиционное строительство из дерева и плотницкое ремесло. М.: Институт наследия, 2019. С.79-105

2. И.А. Кудрявцев. Архитектурно-конструктивные приемы церкви Воскрешения Лазаря Муромского (о. Кижи). Тенденции развития науки и образования. 2020. №66-1, стр. $152-156$. 
3. В.И. Матвиенко. 8889 памятников и 14 миллиардов рублей. Охраняется государством. №5, 2018, стр. 14-16.

4. Серов Е.Н., Миронова С.И. Усиление балок нижнего четверика Преображенской церкви на о. Кижи по новым требованиям служб «Юнеско». СПб. Вестник гражданских инженеров. 2017.- №5, стр. 57-61.

5. С.И. Миронова, С.С. Миронов. Использование акустического детектора и теплового нагрева с помощью волн СВЧ для борьбы с жуками-древоточцами в деревянных строительных конструкциях. «Вестник гражданских инженеров», 2016, №3, стр. 47-51.

6. С.И. Миронова, А.Л. Ковжина, М.Б Москалев, Т.А. Серова. Исследование поражения микроскопическими грибами образцов из сосны и LVL. «Вестник гражданских инженеров», 2015.№2, стр. 145-152.

7. Миронова С.И. А.В. Митракова. Строительные конструкции в памятниках деревянного зодчества (на примере терема в с. Асташово). СПб. Вестник гражданских инженеров. №6, стр. 56-60.

8. Ополовников А.В. Русское деревянное зодчество. Т. 1. М., Искуство, 1986, 310 с.

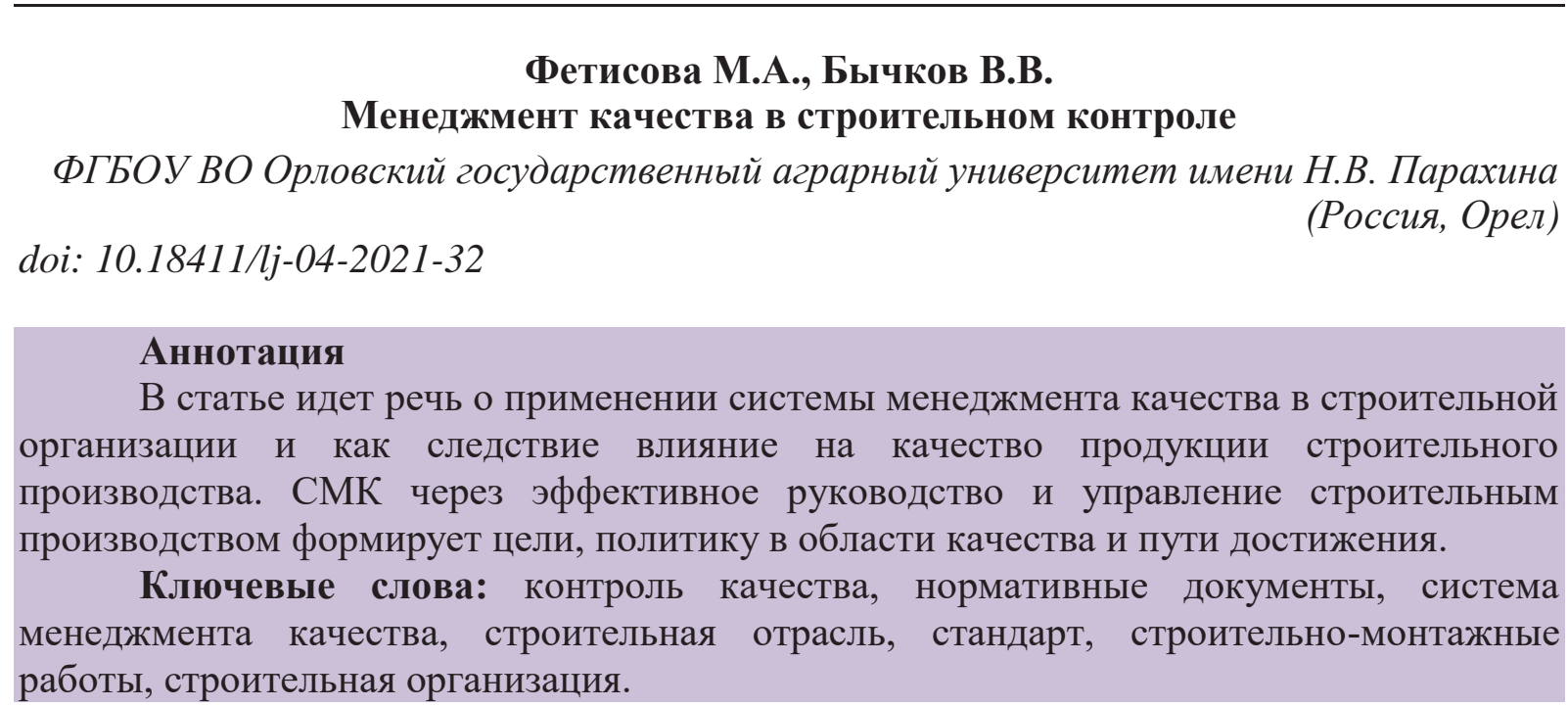

\section{Abstract}

The article deals with the application of a quality management system in a construction organization and, as a consequence, the impact on the quality of products of construction production. The QMS, through effective management and management of construction production, forms goals, quality policy and ways to achieve it.

Keywords: quality control, regulatory documents, quality management system, construction industry, standard, construction and installation work, construction organization.

Для того чтобы строительная организация успешно функционировала, ею нужно эффективно управлять. Когда речь идет об управлении, подразумеваются все стороны менеджмента, который в свою очередь предназначен решать организационные, стратегические вопросы. Система менеджмента качества, как строительной организации, так и любой другой, сформировывает цели, политику в области качества и пути достижения. Данная система предполагает вовлеченность всего персонала в управление процессами по имеющимся показателям.

Целью создания и внедрения системы менеджмента качества является бесперебойная работа строительной организации и производственных процессов, а также отслеживание и предупреждение в будущем проблем, которые препятствуют постоянному росту уровня качества в организации. Выбор модели системы менеджмента является начальным этапом по её внедрению. Затем сравнивают требуемые показатели, устанавливаемые системой, с показателями деятельности строительной организации. После оптимизации и возможной реорганизации процессов в фирме проводится разработка и внедрение документации СМК, осуществляется сертификация согласно стандартам системы менеджмента. Конечным результатом 